\title{
EDITORIAL
}

\section{RECRUITMENT AND RETENTION AS A CHALLENGE OF CONTEMPORARY ARMED FORCES AND SOCIETIES}

In the last week of June 2017, the $14^{\text {th }}$ ERGOMAS Conference was held in Athens, Greece. The abbreviation stands for European Research Group on Military and Society, which was founded in 1986. It is a public, non-profit and ideologically independent professional organization of scientists. They operate through conferences where they meet every other year. The group is actively engaged in various fields: Military Profession, Public Opinion, Mass Media and the Military; Morale, Cohesion and Leadership; Military Families; Civilian Control of the Armed Forces; Gender and the Military; Warriors in Peacekeeping; Military and Police Relations; Violence and the Military; Recruitment and Retention; Veterans and the Society; Military Conflict Management and Peace Economics, and Critical Military Studies. In each of these areas, a coordinator is responsible for the preparation and execution of sessions at conferences.

Dr Tibor Szvircsev Tresch is an ERGOMAS coordinator for recruitment and retention in the modern armed forces, as well as a member of the Editorial Board of the Contemporary Military Challenges. In Athens, we agreed to collaborate on a special thematic issue on this subject. Recruitment and retention in the armed forces is not only a problem the Slovenian Armed Forces and Slovenia have been dealing with in the past few years. Rather, it is a complex phenomenon also encountered by other modern armed forces, societies and countries. On the one hand, they vary greatly with regard to different factors, but at the same time they share the same issues - an insufficient number of military personnel, unsuccessful methods of their retention and insufficiently thought-out concepts of their retirement from the armed forces and return to the labour market. Different countries use different methods to deal with this issue. In some aspects, some of these approaches are even similar. However, the fact remains that all of them use a very intensive, professional and scientific approach, which is also evident from the articles in this special issue. 
With regard to Slovenia's challenges, we can note down that it is time to approach this field from a wider perspective. The problem of recruiting personnel for the Slovenian Armed Forces is not only the problem of the Slovenian Armed Forces, but also Slovenia as a country, which is obliged to ensure national security.

In the article Officer recruitment - improving the process, Johan Österberg, Emma Jonsson and Anna Karin Berglund present the case of the Swedish Armed Forces, where there was a large gap between the number of applicants and the number of individuals who actually started the Officer Programme. Due to this phenomenon, in 2014, a project was launched with the aim to ensure an adequate quality of candidates, thus bridging the differences between the wishes and the abilities of the candidates.

Article The effects of conscript service on the recruitment of professional soldiers in Estonia was written by Tiia-Triin Truus, Kairi Kasearu and Liina-Mai Tooding. The authors have established that a positive attitude towards the defence forces and an individual's intention to join are not formed during the service, but rather preconscription experience and involvement in voluntary organizations related to the military or interior security have a bigger influence.

James Griffith focused on the problem of recruitment for the purpose of the U.S. voluntary reserve forces and explained his findings in the article The United States All-Volunteer Force: emerging (and often unanticipated) issues of recruitment, retention, and readiness. He used the method of identity theory. More on his findings is available in the article.

Can we win this war? Slovenian Armed Forces recruitment and retention challenges 15 years later is the title of the article, in which the author Boštjan Močnik analyzes demographic and economic trends and some other factors related to the recruitment and retention of military personnel, which have significantly influenced and greatly changed the recent manning efforts. He compares them to some other countries and proposes some solutions to "win this war".

The Canadian Armed Forces carried out a comprehensive survey on retention in their reserve and regular forces. The article titled Reserve force: unique considerations and a comparison with regular force issues was written by Joanna E. Anderson, Irina Goldenberg and Jan-Michael Charles. Among other things, they established that the results of the research suggested that regular force members' oft-cited perceptions of reservists as being less dedicated than themselves were unfounded.

All of the above-mentioned authors deal with modern trends in the field of recruitment and retention, while Elad Neemani on the other hand focused on Israel Defence Forces manpower in its early years: from social cohesion to a strategic recruitment and retention crisis. He writes about a topic that is historical and very specific in 
many respects, but when reading about it, it seems as if some problems from those times are timeless.

We express our appreciation to Dr Tibor Szvircsev Tresch for his intensive and very professional cooperation as well as all the assistance in preparing this thematic issue. We wish our readers, enthusiasts of military- and defence-related topics, a beautiful summer and pleasant reading. 